\title{
The sensitivity of Pseudomonas pseudomallei to trimethoprim and sulphamethoxazole in vitro
}

\author{
D. C. J. BASSETT \\ From the Cross Infection Reference Laboratory, Central Public Health Laboratory, Colindale, London
}

SYNOPSIS Twelve out of 14 strains of Pseudomonas pseudomallei were inhibited in vitro by a combination of trimethoprim $1 \mu \mathrm{g}$ per $\mathrm{ml}$ and sulphamethoxazole $20 \mu \mathrm{g}$ per $\mathrm{ml}$ or by lower concentrations. Of the remaining strains, one was marginally more resistant and one was distinctly so. In tests utilizing two of the sensitive strains, inhibitory concentrations of the individual drugs exerted a $\varnothing$ bactericidal effect when combined.

Recent American experience of cases of melioidosis from Vietnam has led to renewed interest in the problems of antibiotic treatment and chemotherapy in this disease. Most commonly, high dosages of combinations of antibiotics have been used, and a minimum of four weeks' treatment has been accepted as necessary because of the danger of relapse (Spotnitz, Rudnitsky, and Rambaud, 1967; Bentz, Rudnitsky, and Kmiecik, 1968; Malizla, West, Brundage, and Walden, 1969; Thin, Brown, Stewart, and Garrett, 1970). Cooper (1968) recommended, for severe forms of the disease, initial treatment with chloramphenicol $12 \mathrm{~g}$, kanamycin sulphate $4 \mathrm{~g}$, and novobiocin $6 \mathrm{~g}$ per day, but this choice of drugs and the necessity for such extreme dosage was questioned by Spotnitz (1968).

Eickhoff, Bennett, Hayes, and Feeley (1970) studied the sensitivity of 10 strains of Pseudomonas pseudomallei in vitro and found that tetracycline, chloramphenicol, novobiocin, and sulphadiazine were the most active of the drugs that they tested. Grunberg, Beskid, Delorenzo, and Titsworth (1969) studied six strains in experimental infections in mice. Chloramphenicol was not tested; of 17 other drugs given orally, chlortetracycline, novobiocin, and sulphamethoxazole were the most active, but there were individual strains resistant to each of these drugs. Both studies thus confirmed the activity of sulphonamides, which had been shown by Miller, Pannell, and Ingalls in 1948, with the successful treatment of experimental melioidosis in hamsters. Sulphonamides have continued to be of value, as in the case described by Maegraith and Leithead (1964) which was successfully treated with a 108-day course of sulphadiazine.

Received for publication 18 March 1971.
Trimethoprim is a potentiator of the action of ${ }^{\mathbb{D}}$ sulphonamides (Bushby and Hitchings, 1968), and $\stackrel{\oplus}{3}$ has been used widely in combination with sulphamethoxazole. Morrison (1970) described a case of chronic melioidosis in which treatment with this combination was successful. The present paper. reports the sensitivities in vitro of 14 strains of $P s$. pseudomallei to trimethoprim and sulphamethoxazole, singly and in combination.

\section{Materials and Methods}

STRAINS OF PS. PSEUDOMALLEI

The following were obtained from the National Collection of Type Cultures: NCTC numbers 1688, $4845,4846,6700,7383,7431,8016,8708,10274$, and 10276. Mr L. R. Hill kindly provided four more? recently isolated strains from the laboratory of the National Collection: these were designated A 52/68, A 55/68, A 125/68, and A 29/70. The last of these was the strain isolated from the case reported by Morrison (1970), in which trimethoprim and sulphamethoxazole were used.

TRIMETHOPRIM LACTATE AND SULPHAMETHO- N XAZOLE

These were kindly provided by $\operatorname{Dr}$ A. S. E. Fowle of the Wellcome Research Laboratories.

MINIMUM INHIBITORY CONCENTRATION (MIC) TESTS

These were carried out on plates of Oxoid DST agar containing $5 \%$ lysed horse blood, with trimethoprim and sulphamethoxazole incorporated either singly $\underset{\vec{D}}{\mathrm{D}}$ or in combination. The drugs were combined always in the proportions of 1 part trimethoprim to 20 parts $\unrhd$ sulphamethoxazole. The plates were prepared 
according to the method of Darrell, Garrod, and Waterworth (1968). An end-point of approximately $90 \%$ inhibition after 24 hours' incubation was used (Bushby and Hitchings, 1968).

\section{TESTS FOR BACTERICIDAL ACTIVITY}

These were carried out in nutrient broth, freed from sulphonamide antagonists by the method of Harper and Cawston (1945). Drugs were added in $0.04 \mathrm{ml}$ of normal saline to $0.3 \mathrm{ml}$ of broth. The inoculum was $0.02 \mathrm{ml}$ of a 1 in 1,000 dilution of an overnight broth culture. Tubes were sealed and mixed continuously by rotation for 24 hours at $37^{\circ} \mathrm{C}$, after which surface viable counts were made on nutrient agar plates. All tests and controls were performed in duplicate.

\section{Results}

Table I shows the MICs of trimethoprim and sulphamethoxazole, tested singly and in combination, against 14 strains of Ps. pseudomallei. Strains were either sensitive to both drugs or relatively resistant to both. Only two of the strains did not show $90 \%$

\begin{tabular}{lllll}
\hline Strain No. & $\begin{array}{l}\text { Trimetho- } \\
\text { prim } \\
(\mu g / m l)\end{array}$ & $\begin{array}{l}\text { Sulpha- } \\
\text { methoxazole } \\
(\mu g / m l)\end{array}$ & $\begin{array}{l}\text { Combination } \\
\text { TMP } \\
(\mu g / m l)\end{array}$ & $\begin{array}{l}S M X \\
(\mu g / m l)\end{array}$ \\
\hline NCTC 6700 & 1 & 5 & $0 \cdot 25$ & 5 \\
A 55/68 & 1 & 10 & $0 \cdot 25$ & 5 \\
A 52/68 & 2 & 5 & $0 \cdot 25$ & 5 \\
NCTC 7383 & 2 & 5 & $0 \cdot 25$ & 5 \\
NCTC 7431 & 2 & 10 & $0 \cdot 25$ & 5 \\
NCTC 10274 & 2 & 10 & $0 \cdot 25$ & 5 \\
NCTC 10276 & 4 & 10 & $0 \cdot 5$ & 10 \\
NCTC 1688 & 4 & 20 & $0 \cdot 5$ & 10 \\
NCTC 4845 & 4 & 40 & $1 \cdot 0$ & 20 \\
NCTC 8016 & 8 & 20 & $1 \cdot 0$ & 20 \\
A 29/70 & 8 & 40 & 1.0 & 20 \\
A 125/68 & 8 & 40 & 1.0 & 20 \\
NCTC 4846 & 8 & 40 & $2 \cdot 0$ & 40 \\
NCTC 8708 & $>8$ & 80 & $4 \cdot 0$ & 80 \\
\hline
\end{tabular}

Table I Minimum inhibitory concentrations of trimethoprim and sulphamethoxazole against 14 strains of Ps. pseudomallei inhibition in the presence of trimethoprim $1 \mu \mathrm{g}$ per $\mathrm{ml}$ combined with sulphamethoxazole $20 \mu \mathrm{g}$ per ml and were thus more resistant than strain A 29/70. The difference in the case of NCTC no. 4846 was slight, and was not apparent when the drugs were tested separately, but the greater resistance of NCTC no. 8708 was evident in all tests.

Against seven of the 14 strains the combination of drugs was more effective than either drug alone at the same concentration, but the MIC of sulphamethoxazole in the combination was never less than half the MIC of sulphamethoxazole alone.

Table II shows the viable counts obtained before and after 24 hours' incubation in broth containing various concentrations of the drugs. Strain A 52/68 was chosen to represent the more sensitive strains; inhibition was caused by trimethoprim $1 \mu \mathrm{g} / \mathrm{ml}$ and by sulphamethoxazole $20 \mu \mathrm{g} / \mathrm{ml}$ and the combination of the two showed some bactericidal action. Strain A 29/70 was more resistant but came from a patient who had been successfully treated with the combined drugs: the drugs singly caused no significant inhibition at the lower concentrations but did inhibit markedly in combination. At the higher concentrations, sulphamethoxazole alone was inhibitory and the combination was bactericidal. Against the most resistant strain, NCTC 8708, the higher concentrations of drugs combined were definitely inhibitory, but there was no bactericidal action.

\section{Discussion}

Twelve of the 14 strains of Pseudomonas pseudomallei tested were inhibited in vitro by a combination of trimethoprim $1 \mu \mathrm{g}$ per $\mathrm{ml}$ and sulphamethoxazole $20 \mu \mathrm{g}$ per $\mathrm{ml}$. These levels can be maintained in vivo with normal doses of the drugs. The combination of drugs at these concentrations was shown to have a bactericidal effect against one of the more sensitive strains: the more resistant strain A 29/70 was inhibited but not killed, except by higher concentrations. The fact that A 29/70 was isolated from a patient who responded favourably to subsequent treatment with these drugs suggests that infections with any of the 12 sensitive strains would be treatable similarly. One of the remaining two strains was

\begin{tabular}{|c|c|c|c|c|c|c|c|}
\hline $\begin{array}{l}\text { Trimethoprim ( } \mu g \text { per } m l \text { ) } \\
\text { Sulphamethoxazole ( } \quad \text { per } m l)\end{array}$ & $\begin{array}{l}1 \\
0\end{array}$ & $\begin{array}{r}0 \\
20\end{array}$ & 20 & $\begin{array}{l}8 \\
0\end{array}$ & $\begin{array}{r}0 \\
160\end{array}$ & $\begin{array}{r}8 \\
160\end{array}$ & $\begin{array}{l}\mathbf{0} \\
\mathbf{0}\end{array}$ \\
\hline $\begin{array}{ll}\text { Strain no. and log initial count } & \\
\text { A } 52 / 68 & 3.75 \\
\text { A } 29 / 70 & 3.25 \\
\text { NCTC } 8078 & 4 \cdot 20\end{array}$ & $\begin{array}{l}7 \cdot 30^{2} \\
9 \cdot 50 \\
-\end{array}$ & $\begin{array}{l}7 \cdot 00 \\
9 \cdot 05 \\
-\end{array}$ & $\begin{array}{l}2 \cdot 65 \\
6 \cdot 35 \\
-\end{array}$ & $\begin{array}{l}\text { Not done } \\
9.05 \\
-\end{array}$ & $\begin{array}{l}- \\
-\end{array}$ & $\underset{5.95}{<1 \cdot 70}$ & $\begin{array}{l}9 \cdot 00 \\
9 \cdot 25 \\
8 \cdot 70\end{array}$ \\
\hline
\end{tabular}

Table II Action of varying concentrations of trimethoprim and sulphamethoxasole on Ps. pseudomallei

${ }^{1}$ Log viable count after 24 hours 
marginally more resistant; the other was distinctly more resistant both to trimethoprim and to sulphamethoxazole, although it had been isolated before the introduction of trimethoprim.

The two drugs commonly act synergistically, and apparently have their effects at different points on the same metabolic pathway (Darrell et al, 1968). These authors described the development of resistance to the drugs in laboratory experiments on Escherichia coli and Proteus spp. A high level of resistance to trimethoprim readily developed, but was blocked in the presence of sulphonamide. However, the parallelism shown between the trimethoprim and sulphamethoxazole resistances of the various strains of Ps. pseudomallei suggests the possibility of a common mode of resistance to the two drugs.

Because Ps. pseudomallei naturally occurs in soil and water, and infection comes from this source, the usefulness of a drug depends on the proportion of sensitive strains in the environment. This proportion should not be affected by the emergence of drug resistance in a treated case.

Long-term treatment with trimethoprim and sulphamethoxazole without serious side effects was reported by Jenkins, Hughes, and Hall (1970). It would seem, therefore, that this might be a useful alternative to antibiotic therapy for the treatment of melioidosis, provided that the sensitivity of the infecting organism is established.

\section{References}

Bentz, R. R., Rudnitsky, J., and Kmiecik, J. E. (1968). Melioidosis: a 2-year experience at Valley Forge General Hospital. (Abstr.) InTransactions of the 27th VA-Armed Forces Pulmonary Disease Research Conference, p. 88. Veterans administration, $\frac{\sigma}{\bar{D}}$ Washington, D.C.

Bushby, S. R. M., and Hitchings, G. H. (1968). Trimethoprim: a sulphonamide potentiator. Brit. J. Pharmacol., 33, 72-90. Cooper, E. B. (1968). Treatment of melioidosis. J. Amer. med. Ass.,
204, 176.

Darrell, J. H., Garrod, L. P., and Waterworth, P. M. (1968). Trimethoprim: laboratory and clinical studies. J. clin. Path., 21, 202-209.

Eickhoff, T. C., Bennett, J. V., Hayes, P. S., and Feeley, J. (1970). $\vec{\omega}$ Pseudomonas pseudomallei: susceptibility to chemotherapeutic agents. J. infect. Dis., 121, 95-102.

Grunberg, E., Beskid, G., Delorenzo, W. F., and Titsworth, E. (1969). Activity of selected antimicrobial agents against the Pseudo- $N$ monas pseudomallei infection of mice. Amer. Rev. resp. Dis.,
101, 623-626.

Harper, G. J., and Cawston, W. C. (1945). The in-vitro determination of the sulphonamide sensitivity of bacteria. J. Path. Bact., 57, 59-66.

Jenkins, G. C., Hughes, D. T. D., and Hall, P. C. (1970). A haematological study of patients receiving long-term treatment with trimethoprim and sulphonamide. J. clin. Path., 23 392-396.

Maegraith, B. G., and Leithead, C. S. (1964). Melioidosis: a case $\mathbb{D}$ report. Lancet, 1, 862-863.

Malizia, W. F., West, G. A., Brundage, W. G., and Walden, D. C. (1969). Melioidosis: laboratory studies. Hlth Lab. Sci., 6, 음 27-39.

Miller, W. R., Pannell, L., and Ingalls, M. S. (1948). Experimental chemotherapy in glanders and melioidosis. Amer. J. Hyg., 47, $\overrightarrow{0}$ 205-213.

Morrison, I. M. (1970). Chronic melioidosis. Proc. roy. Soc. Med. 63, 289-290.

Spotnitz, M., Rudnitzky, J., and Rambaud, J. J. (1967). Melioidosis pneumonitis. J. Amer. med. Ass., 202, 950-954.

Spotnitz, M. (1968). Treatment of melioidosis. J. Amer. med. Ass., 204, 176.

Thin, R. N. T., Brown, M., Stewart, J. B., and Garrett, C. J. (1970). Melioidosis: a report of ten cases. Quart. J. Med., 39, 115-127. (D) 